\title{
Peer Effects in Adolescent BMI: Evidence from Spain
}

\begin{abstract}
:
This paper extends the recent literature on the influence of peers on adolescent weight on three new fronts. First, based on a survey of secondary school students in Spain in which peers are formed by nominated classmate friends, we find a more powerful positive and significant causal effect of friends' mean BMI on adolescent BMI than previous US-based research. These results are in line with international data which show that peer group contact tends to vary across countries. Our findings cover a large set of controls, fixed effects, the testing of correlated unobservables, contextual influences and instrumental variables. Second, social interactions are identified through the property of intransitivity in network relationships. Finally, we report evidence of a strong, positive effect of peer pressure on several subgroups of adolescents in an attempt to study their vulnerability to social influences.
\end{abstract}

Keywords: Peer effects, Adolescent behaviour, Obesity/overweight 


\section{Introduction}

Obesity is a global public health problem that is not restricted to the wealthy nations. The rapid increase of the obesity epidemic in recent decades is particularly alarming in children and adolescents, as the condition may pass into adulthood and create a growing health burden for the coming generations. According to the CDC report (2010) the prevalence of overweight in US teenagers, aged 12-19 years, has more than doubled in recent decades, reaching $17.8 \%$ in 2005-2006. This upward trend is also observed in European countries. The Health Behaviour School-aged Children survey conducted in 2001-02 indicated that $24 \%$ of 13 -year-old girls, $34 \%$ of 13 -year-old boys, $31 \%$ of 15 -year-old girls and $28 \%$ of 15 year-old boys in Europe were overweight. ${ }^{1}$ Empirical evidence shows that overweight during childhood and adolescence is a major cause of ill health in those ages and also in adulthood, increasing the risk of hypertension, cholesterol, sleep apnoea, diabetes type 2 , low self-esteem, and discrimination in education and work settings (Dietz, 1998; Reilly et al., 2003).

Research on the determinants of child/adolescent overweight has highlighted the influence of parents (e.g., genes, transmission of values and norms, food choices, education), race and ethnicity, the role of food availability and prices, and the emergence of an "obesogenic environment" through changes in home, school, transport and urban policies and commercial food activities which encourage physical inactivity and poor dietary practices (Koplan et al., 2005). In the last decade or so, a new body of literature has emerged in the field of health economics associated with social interaction models, which stresses the influence of peers on adolescents' health status. Several papers have suggested that friends or classmates have a significant positive impact on health-related behaviours in the young, such as smoking, binge drinking or illicit-drug use (e.g., Norton et al., 1998; Gaviria and Raphael, 2001; Powell et al., 2005; Lundborg, 2006; Clark and Lohéac, 2007; Harris and González, 2008, Halliday and Kwak, 2012). However, far less is known about the effect on the obesity status of the population of social networks - ties between friends, siblings, spouses, neighbours, and so on. Using a social network of adult people with repeated measurements over a period of 32 years, Christakis and Fowler (2007) concluded that networks of this kind facilitate the spread of obesity. Similarly, the studies by Trogdon et al.

\footnotetext{
${ }^{1}$ A geographical pattern can be observed in European countries. The UK presents the highest figures for overweight for these age groups, but it is followed by a group of southern European countries - Greece, Italy, Portugal and Spain. The Scandinavian and central European countries show the lowest levels (WHO, 2007).
} 
(2008), Halliday and Kwak (2009) and Renna et al. (2008) used cross-sectional surveys of health-related behaviours in a sample of American adolescents and reported a positive association between friends' weight and adolescent body weight.

This paper contributes to the recent literature on peer effects and adolescent body weight on three new fronts. First of all, we use for the first time data from a southern European country (Spain) to replicate a finding commonly reported in US data. Anecdotal evidence suggests that peer effects will be greater in Spain than in the US, perhaps reflecting a more intense social life and stronger peer pressure in Mediterranean countries. Secondly, following Bramoullé et al. (2009) we identify social interactions using the property of intransitivity in network relationships. Thirdly, we examine the impact of peer pressure on alternative subgroups of students in an attempt to shed new light on the relationship between adolescent networks and body weight. We use data from a single survey of secondary school students in Catalonia (Spain) conducted in 2008 which compiled a rich set of personal data and a wide range of school characteristics and parental backgrounds. An interesting feature of this dataset is that students were asked to identify their specific friends in class (without any limitation on number or gender), allowing us to construct a precise definition of friendship.

After accounting for a large set of controls, school- and neighbourhood-specific fixed effects, the testing of correlated unobservables and contextual effects and the use of instrumental variables estimation, our dataset supports the hypothesis of a more powerful positive and significant causal effect of friends' mean BMI on adolescent weight than that found in previous US-based research. Finally, other large and significant positive effects were found when new and alternative peer pressure definitions were considered, thus helping to identify the demographic groups of adolescents that are most vulnerable to social influences. The paper is organized as follows. Section 2 presents international evidence of peer contact across countries and discusses identification issues. Section 3 describes the data and presents the empirical methodology. Section 4 reports the main results, and finally section 5 concludes.

\section{Social interactions within the classroom}


Adolescence is recognized to be a critical developmental period in which young people face many new situations: continually adjusting to physical changes, exploring their sexuality, establishing their personal identity, seeking greater independence and increasingly relying on friendship groups. This period offers opportunities for progress but also presents risks to health and well-being (Irwin et al., 2002). It is during these years that social interactions with friends, classmates, neighbours etc. are most intense, decisively affecting adolescents' health-related behaviours and reinforcing norms or values which ultimately shape individual behaviour. Being liked and accepted by peers is crucial for adolescents' health status, and interactions with friends tend to improve social skills and strengthen the ability to cope with stressful events. In contrast, those who are not socially integrated are far more likely to exhibit difficulties with their physical and emotional health. The influence of peers on adolescents' health is a complex issue that provides both protective and risk factors (Berndt, 1999). ${ }^{2}$

\subsection{International Evidence}

According to the latest edition of the Health Behaviour in School-aged Children survey (2005-2006), the most comprehensive study on health patterns among young people in Europe and North America, peer group pressure varies greatly across countries. These data show the existence of significant cross-country differences in the size of friendship groups, which is taken as a proxy indicator of exposure to peer influences (WHO, 2008). While adolescents in English-speaking countries (Canada, the US and the UK) and Scandinavian countries report high percentages of groups containing three or more close friends of the same gender (around 80-90\%), in Mediterranean and eastern European countries these percentages are far lower. Notice that group size is crucial, as children with few friends tend to have fewer opportunities to develop their social skills. Moreover, difficulties in relating to others can often perpetuate isolation, with negative consequences for selfesteem, depression or poor school adjustment (WHO, 2008).

The above data also indicate the existence of large cross-national differences in the amount of time young people spend with their friends, which is a strong predictor of peer influence. In principle, one might expect to find a positive association between frequent contact with friends and a higher likelihood of initiating or maintaining different types of

\footnotetext{
${ }^{2}$ See Cotterell (2004) for an excellent analysis of how adolescents are in general influenced by the type of
} social ties emerging from a variety of settings like cliques, crowds or gangs. 
risky behaviours. ${ }^{3}$ For instance, among 15 -year-olds, the percentage of boys (girls) meeting with friends four or more evenings per week is $28 \%(20 \%)$ in the US, far lower than the respective figure of $41 \%(31 \%)$ for Spain. ${ }^{4}$ Note that behind this geographical variation in adolescent social networks, cross-country differences persist in socio-cultural, religious, life-style and environmental patterns which influence the identity and socialization process of youth and, thus, the behaviour of peer groups.

Based on this evidence, the first goal of this paper will be to verify the hypothesis that peer effects on adolescent body weight (proxied by the BMI) are greater in our dataset than in the findings reported for the US, bearing in mind that we are comparing two geographical areas characterized by specific economic, socio-cultural and environmental patterns.

\subsection{Identification Issues}

The empirical evidence on peer effects suffers from what is known as the reflection problem (Manski, 1993) which influences the identification of endogenous social effects. According to this framework, individual and peers' weight may be correlated for three different reasons: (i) the direct influence of peers' weight on individual weight, which produces the "endogenous effect" and implies a causal interpretation; (ii) the indirect influence on individual weight caused by the exogenous characteristics of the peer group ("exogenous or contextual effects") and (iii) the influence of a common set of unobservables on both individual and peers' weight ("correlated effects"). The first two effects reflect social interactions - albeit with different policy implications - whereas correlated effects are a statistical, non-social phenomenon (Manski, 1993, 2000). Given the plausibility of this hypothesis, the main empirical challenge with observational data in the literature is to discriminate between or disentangle these three effects and to identify a causal relationship of peer influence on adolescent weight. Another challenge when analyzing peer effects is the fact that schools, classrooms and peer groups are not formed randomly. ${ }^{5}$

\footnotetext{
${ }^{3}$ However, peer contact is also important for the development of protective factors (i.e., participation in physical activity or youth club membership) against unhealthy life-styles.

4 These country-specific differences are smaller among 13-year-olds, as meeting with friends increases gradually with age.

5 The usual solution has relied on exploiting experimental or quasi-experimental designs to separate social effects in the classroom (which are the combination of endogenous and exogenous peer effects). On the other hand, using observational data, recent literature has focussed on identifying exogenous variations to explain the formation of peer groups.
} 
We deviate from the strategy adopted by certain studies to identify the causal peer effect (Norton et al., 1998; Case and Katz, 1991, Gaviria and Raphael, 2001; Lundborg 2006; Trogdon et al., 2008 and Renna et al., 2008, Halliday and Kwak, 2012) which assumes that only one type of social effect exists - the endogenous effect - and that contextual influences are non-existent. This is similar to hypothesizing that the influence that peers may exert on adolescent weight is channelled through the reference group weight status (Trogdon et al., 2008). We consider that this assumption is questionable in the context of our dataset in which the peer group of each adolescent is defined as nominated classmate friends. As long as these friends interact with each other not only at school but possibly outside it, namely at each other's residences, adolescents can be influenced by the exogenous characteristics (e.g., diet, physical exercise, smoking status, income, education or occupation) of their peers' parents, giving rise to contextual effects. Therefore our strategy here is to control for the presence of such exogenous or contextual influences by including controls denoting peers' average characteristics.

Regarding the problem of correlated effects, Moffitt (2001) makes a useful distinction between two generic sources of such spurious influences: a) sorting and endogenous group membership in which preferences or other forces lead certain individuals to be grouped together; and b) the existence of common environmental factors in the school district or neighbourhood (Soetevent, 2006). The latter is the case, for instance, of classmates eating the same school $\operatorname{diet}^{6}$ or doing the same sports at school, and of parents when choosing where to live, since they are indirectly choosing their children's peers at neighbourhood and school level. Here it could be argued that the presence of certain unobserved factors (i.e., parks, sports facilities) leads families to sort into school areas or districts which ultimately affect bodyweight in a similar manner. We address these issues by including school- and neighbourhood-specific fixed effects (Lundborg, 2006; Clark and Lohéac, 2007; Trogdon et al., 2008 and Renna et al., 2008, Halliday and Kwak, 2012). Additionally, an extended set of average lifestyle behaviours defined at classroom level are included to pick up further correlated effects related to sorting. ${ }^{7}$ Finally, we apply instrumental variable (IV) estimation to solve the reflection problem using as instruments the characteristics of the respondents'

\footnotetext{
${ }^{6}$ In Catalonia lunch diets at schools are controlled by the regional government through regular inspections.

${ }^{7}$ Kang (2007) has shown that weaker students have closer interaction with other weak students than with strong students, thus inducing sorting out effects.
} 
friends-of-friends who are not friends with the respondent, in accordance with the intransitivity property of network relationships (Bramoullé et al., 2009).

A further problem outlined by Manski (1993) is that researchers rarely know who exactly constitutes the peer group and have to impose their own ad-hoc definition of it. Treating peer effects as a consequence solely of predetermined peer features such as ability captures only part of the situation: peer group may come into being through unobservables such as leisure activities or lifestyle conditions. Whilst school and class composition is determined by neighbourhood characteristics such as average income per capita, the make-up of the real reference group (peers within the classroom) relies on other sociological factors. Bishop et al. (2004) affirms that teenagers interact with each other based on time allocation between activities according to clique norms (such as extracurricular activities and socializing). Therefore, it is important to estimate peers' influence by means of databases that account for nominated friendship relationships. Fortunately, our cross-sectional dataset permits us to use nominations of classroom friends in order to form reference groups.

\section{Data and Method}

We use data from a single representative survey of secondary school students in Catalonia, one of Spain's richest and most densely populated regions, collected between February and June 2008. The survey was targeted at secondary students in four specific academic years: the last two years of compulsory secondary education (14-16 years old) and the two years of higher secondary education (16-18 years old). The questionnaires were completed by students, and maths teachers were approached to participate in the survey and help with student data collection. The questionnaire (supplied on-line with questions presented randomly) contained six blocks of questions: personal data (including anthropometric information), school characteristics, maths teaching questions, parental background information, conscientiousness and motivation, and lifestyle habits. ${ }^{8}$ The final sample contains information on more than 3,000 students from 91 high schools. ${ }^{9}$

\footnotetext{
${ }^{8}$ Since not all high schools had computer room facilities or sufficient time available, some schools received the questionnaire in paper format. None of the students had access to the questionnaire prior to responding, thus avoiding the risk of attrition effects. Students were free not to respond to some questions.

${ }^{9}$ As the under-representation of some specific areas or schools due to their managerial characteristics (public, semi-private or private) might have given rise to sample selectivity, administrative information was obtained from the Catalan Ministry of Education to ensure the representativeness of the sample.
} 
Our cross-sectional dataset presents a number of advantages over the data used in previous studies. First, we define peer groups using nominated friends within the classroom. Few other studies have been able to define peer pressure at such a precise level. ${ }^{10}$ Second, in contrast to the Add Health data, in which students were limited to listing up to 10 friends (5 male and 5 female), in our dataset students could identify or nominate as many close classroom friends as they wished. Third, like Add Health data, we could consider more sophisticated social networks such as asymmetries in classmates' relationships. Hence, in addition to the "nominated friends" peer effect formed by all listed classroom friends chosen by each adolescent, a narrower definition could be derived ("mutual friends" peer contact) where the reference group is composed only by those who also reciprocate the friendship. However, we prefer the first peer definition because in general students are affected not only by their mutual relationships; even if some peers do not correspond reciprocally, students are actually influenced by those who they have nominated (Halliday and Kwak, 2012). More importantly, this provides us with information on the characteristics of the respondents' friends-of-friends who are not friends with the respondent. Fourth, our social networks are more connected and less varied than those in the Framingham Heart Study, and are similar to those in the Add Health, as they take place within the same classroom (Cohen-Cole and Fletcher, 2008). Fifth, the data allow us to address the issue of endogenous sorting. While students cannot decide which class they belong to and so cannot sort themselves into classes with other pupils who are similar to them, sorting across schools may take place through parents' decisions regarding where to live based on the quality of schools in the area (Lundborg, 2006). ${ }^{11}$ In order to account for this effect, our estimations will include school- and neighbourhood-specific fixed effects. Finally, as noted above, the data include information regarding juvenile behaviour and social networks from a southern country in the EU characterized by a socio-cultural and environmental context which favours an intense social life and which ultimately affects the formation and dynamics of peer group pressure.

The dependent variable of this study is adolescent BMI, calculated as the ratio of individual weight (measured in kilograms) to squared height (measured in metres). Since weight and height information is self-reported by each interviewee, there is a potential for

\footnotetext{
10 The exceptions are Clark and Lohéac (2007), Trogdon et al. (2008), Renna et al. (2008) and Halliday and Kwak $(2009$, 2012) who used the same dataset, the National Longitudinal Study of Adolescent Health (Add Health), and Christakis and Fowler (2007) who used the Framingham Heart Study.

${ }^{11}$ In Spain schools do not sort students according to ability.
} 
measurement error as, in general, individuals of both sexes consider themselves to be taller and thinner than they actually are. We therefore partially adjusted self-reports of height and weight by applying a standard correction procedure (e.g. Cawley, 2000; Chou et al., 2004; Cawley and Burkhauser, 2008). To do so, we estimated the relationships between measured and self-declared weight (height) found using a sample of adolescents of the same age group (based on the Catalan Health and Examination Surveys, 2006) ${ }^{12}$ and transferred these values to our dataset. Notwithstanding, we also ran parallel estimations without adjusting for self-reporting error to compare the magnitudes of the peer effect variable.

Our econometric approach proceeds by initially estimating the following regression equation. The dependent variable is the (corrected) BMI of pupil $i$ within peer group $j$ in class $c$ and in school $s$. The adjusted models are as follows,

$$
B M I_{i j c s}=\beta_{0}+\beta_{1} B M I_{j c s}+\beta_{2} X_{i c s}+\beta_{3} Z_{j c s}+\beta_{4} X_{c s}+\lambda_{s}+\lambda_{n}+\varepsilon_{i c s}
$$

where our variable of interest $\left(B M I_{j c s}\right)$ is the average (corrected) BMI "nominated friends" within the classroom representing our peer effect measure, ${ }^{13} X_{i c s}$ represents the individual set of covariates considered, $Z_{j c s}$ stands for the average characteristics of their network of friends and $\varepsilon_{i c s}$ is the individual-specific error term. Note that in this equation contextual effects are captured by $\beta_{3}$ and correlated effects emerging from common environmental factors are addressed by using school-specific fixed effects $\left(\lambda_{s}\right)$ and also neighbourhoodspecific fixed effects $\left(\lambda_{n}\right)$ (captured by the residential postal code and the school's postal code). ${ }^{14}$ This set of fixed effects would eliminate any unobserved school or neighbourhood characteristic that might influence the weight of subjects and peers who are in the same classroom and school or who are exposed to the same local environment. Equation (1) further controls for the influence of correlated unobservables related to sorting. Specifically, we considered a set of average lifestyle behaviours defined at the classroom level to reflect other correlated effects $\left(X_{c s}\right)$. As commented above, we also added

\footnotetext{
12 OLS regressions of measured height (weight) on self-reported height (weight) gender, age and age square were derived.

${ }^{13}$ Note that adolescent BMI was subtracted from the computation of peers' weight.

${ }^{14}$ Weight and BMI display dissimilarities based on the district of residence - see Mora (2010) for observed differences within the city of Barcelona, which is representative of the Catalan case.
} 
interaction terms of average behaviour in the group with individual behaviour to measure how similar students were to their friends. The argument here is that if these further covariates, which might be related to individual BMI, turn out not to be statistically significant, then exogenous characteristics, due either to sorting or to common environmental factors, would not affect our peers' impact measure.

As individual controls, we use a long list of covariates $\left(X_{i c s}\right)$ including adolescent characteristics (age, gender, immigrant status, smoking status, alcohol consumption, sleeping time, number of hours reading books and watching TV), family characteristics (family type, difference in years between the mother and the adolescent, mother's education and health status, parental involvement in homework ${ }^{15}$ and some class-level characteristics (percentage of mothers with university education; percentage of female students and percentage of female students within cliques).

In accordance with the thesis of Heckman et al. (2006), which proposed that (latent) noncognitive skills and cognitive skills are equally important factors for a successful social and economic life and for the adoption of less risky behaviour, our econometric specification includes a measure of individual conscientiousness. As the questionnaire asked for information on conscientiousness (one of the five components of personality, the one related to ability), this variable was constructed through a factor analysis. ${ }^{16}$ Although other measures can be affected by peers, personality traits are specific to each individual and are not so likely to be influenced. So we are able to include this covariate as a proxy for student fixed effects, and it constitutes a different source of ability. Table 1 shows the definition of the list of the covariates considered in all our estimations.

[Insert Table 1 about here]

\footnotetext{
15 Other covariates such as physical exercise, health status and extracurricular activities or father's health status were not included due to their lack of statistical significance. These and other covariates were finally not considered for efficiency reasons. For instance, following Calvó-Armengol et al. (2009) we used the number of nominations to control for unobserved network-specific components.

${ }^{16}$ Due to time constraints for applying the survey, we conducted several interviews with psychologists in order to ensure that the relevant questions were included. Seven questions were asked about conscientiousness. Specifically, we used the following questions: I am exacting in my work; I follow a schedule; I get chores done right away; I pay attention to details; I leave my belongings around; I make a mess of things; I shirk my duties. We computed Cronbach's alpha statistics for the scale formed from the pairs of variables (0.76). A factor analysis allowed us to construct two factors related to personality. The KaiserMeyer-Olkin measure of sampling adequacy was satisfactory (0.81). Accordingly, the factor scores were rescaled to variables ranging from 0 to 1 , indicating the degree of personal conscientiousness.
} 
Notice that the above estimations consider the average (corrected) BMI of "nominated friends" as the central peer influence, although our ultimate goal is to explore alternative peer effect definitions as a sensitivity analysis. The issue of the endogeneity of the peer pressure variable will be addressed by instrumental variable estimation in the next stage.

\subsection{Estimation}

We address the issue of the potential endogeneity or bi-directionality of the peer relationship through the estimation of equation (1) using IV estimation. Some previous literature reports have assumed that contextual effects are absent (the exclusion restriction) and hence average background characteristics of peers can be used as instruments for peer pressure. ${ }^{17}$ This identifying assumption in principle would be violated if the selection of friends, and by implication the selection of friends' parents, is correlated with BMI. In that case, friends' parental characteristics would still be correlated with the error term in the main equation.

We deviate from this approach, and follow the identification of peer effects of Bramoulle et al. (2009) which assumes the presence of intransitivity in the friendship network. This means that, based on our dataset, we can use the mean attributes of the respondents' friends-of-friends who are not friends with the respondent as valid instruments for our peer effect variable. Specifically, our instruments refer to mothers' years of education, average age and the share of single/divorced parents. According to these authors, peer influences are identified, even assuming the presence of correlated unobservable effects. In any case, although we feel that this approach is still an improvement over prior IV methods, we are aware it does not solve completely the selection issue.

\section{Empirical results}

\subsection{Descriptive data}

\footnotetext{
17 While some papers have used friends' parental obesity (Cawley 2000, Brunello and D'Hombres, 2007; Trogdon et al. 2008 or Renna et al. 2008), others have relied on other background parental information (e.g., living in single-parent families or in an apartment, parents born outside the country, parental health status or college education) when analysing other health outcomes (Gaviria and Raphael, 2001; Lundborg, 2006; Halliday and Kwak, 2012).
} 
The average BMI of adolescents in our sample was 21.81 (25.45 among the overweight group), and the prevalence of overweight and obesity was $16.5 \%$ - close to the average Spanish levels (17\%) but below US levels (17.6\% for adolescents aged 12-19). ${ }^{18}$ Interestingly, the average BMI of "nominated friends" peer group (21.78) was slightly lower than the individual BMI of the whole sample. This suggests that fatter students are less likely to be nominated by the rest of students, and so peer groups have a slightly lower body weight. ${ }^{19}$

Note that the mean number of "nominated friends" in our dataset is 6.59 (6.36 among males and 6.81 among females). These figures are notably higher than those reported by studies based on the Add Health database, although this is probably due to the upper limit placed on friend nominations in the US database. As the above mean difference according to gender is statistically significant $(\mathrm{p}$-value $=0.00)$ we split the sample by gender in order to explore peer impact on individual BMI. However, about $10.8 \%$ of students do not list anyone as a friend. To have a precise idea of the variability of our peer pressure covariate, Figure 1 presents the distribution of friends' nominations by BMI status. Overweight students tend to nominate fewer close friends (6.73) than their normal-weight counterparts (7.08) and, although the data are not shown, tend to receive less reciprocity from their nominations than their normal-weight counterparts. The ratio between the number of students' nominations as friends and the number of times nominated is 0.98 for overweight adolescents but considerably lower, 0.75 , for normal-weight teens. This result is likely to condition inference results when asymmetries are considered. Thus, the overweight do not tend to nominate as much as they are nominated by their classmates.

\section{[Insert Figure 1 about here]}

Students tend to self-select their friends within the classroom according to a wide range of characteristics (including academic skills, sport exercising, music activities, etc.) perhaps as an attempt to reinforce their own behaviour, but our argument is that they do not base

\footnotetext{
18 The overweight category was defined using the age- and gender-specific international cut-off points calculated by Cole et al. (2000). Following the recommendations of the International Obesity Task Force, by pooling cross-sectional data on BMI for children from six countries (Brazil, Great Britain, Hong Kong, the Netherlands, Singapore and the United States) and using the centile based method (ensuring that at age 18 they matched the adult cut off of $30 \mathrm{~kg} / \mathrm{m}^{2}$ ) these authors were able to calculate BMI cut-off points for overweight and obesity for children aged 2-18 years.

19 This is consistent with evidence showing that 10- to 11-year-old children prefer as friends other children with disabilities to children who are overweight (Dietz, 1998).
} 
their nominations on BMI or anthropometric measures. In this respect, our data show that the share of overweight students nominating and receiving reciprocity from those similar to them differed little from the percentage found in their normal weight counterparts $(0.158$ and 0.175 , respectively) but the difference was not statistically significant. Finally, based on several checks, the regression estimations controlled the peer impact variables taking into account average peer characteristics.

Finally, the mean age of our sample of adolescents was around 16 years old and $52 \%$ were females (Table 1). Almost 40\% stated that they had drunk alcohol during the previous weekend and $15 \%$ reported smoking on a daily basis. Interestingly, around $30 \%$ of adolescents' mothers had completed university studies; $14 \%$ of adolescents stated that their mothers had poor health status and almost 50\% declared no family involvement in homework.

\subsection{Peer influence}

Table 2 reports a set of OLS estimations of equation (1) accounting for several econometric specifications. However at this stage contextual effects are not considered. In these estimations both the dependent and the network BMI variable were adjusted to correct for self-reporting error. ${ }^{20}$ We use robust standard errors taking into account clustering of observations at the classroom level. The first column, which excludes any controls and fixed effects, shows a positive relation between adolescent BMI and mean peer BMI in our sample of Spanish teenagers. An increase of 1 unit in the average BMI of "nominated friends" was associated with a 0.17 point increase in the respondent's BMI, which corresponds to a marginal effect of $17.07 \%$. In column (2) we estimate the model including both adolescent and family controls. The results indicate that friends' weight is correlated with an adolescent's own weight even after controlling for this list of covariates. As expected, the peer pressure falls considerably, although it remains statistically significant. Now, the estimated marginal effect is around $10.79 \%$. Column (3) includes classroom-level characteristics as additional controls. We find that the "nominated friends" peer effect is still positive and statistically significant, with an estimated marginal effect of $9.08 \%$. Finally, in a further step, in columns (4) and (5) we estimate the model adding school- and neighbourhood-specific fixed effects under the assumption that weight or BMI

\footnotetext{
20 The peer effect impact is slightly lower when individual BMI is not adjusted for misreporting error.
} 
may display disparities depending on the school and/or district of residence. Our results now show that the "nominated friends" peer effect goes to zero and becomes irrelevant in explaining students' BMI. ${ }^{21}$ This finding could be partly due to the fact that the fixed effects now capture the unobserved heterogeneity which was previously captured by the rest of the covariates. In any case, this result is not due to a lack of sufficient statistical variation in adolescent BMI and the peer pressure measure as shown by Figure 2. This figure, which displays the variation in BMI average peer behaviour net of the average of the peer averages in a school using Gaussian kernel functions, illustrates the existence of sufficient variation in BMI and, as expected, indicates that the larger the group (i.e., at the school level) the lower is the dispersion observed. ${ }^{22}$

[Insert Table 2 \& Figure 2 about here]

As an additional step, Table 3 extends the set of OLS regressions to incorporate the existence of contextual effects and to test whether the presence of correlated unobservables related to sorting is affecting the results. The estimates in column (6), which introduces as peers' average characteristics the same list of individual covariates into the reduced form, shows that, with the exception of very limited evidence for mother's poor health status at the peer group level, none of such covariates display statistical significance. As a consequence, we can assume that there is no evidence for contextual effects in our database. Similarly, column (7) in Table 3, which included average lifestyle features at the classroom level, would suggest that endogenous sorting perhaps is not a major problem in our data. ${ }^{23}$

[Insert Table 3 about here]

We are now ready to present (Table 4) the results of the IV estimation of equation (1) using intransitivity in peer groups (section 3.1) to control for the potential endogeneity of our

\footnotetext{
${ }^{21}$ Interestingly, we conducted a falsification test to verify whether our peer measure (assuming the same set of controls) exerted any effect on individual height which is taken as variable not subject to influences by friends. The results found no influence for average peers' BMI on height.

${ }^{22} \mathrm{Next}$, based on our identification strategy, results for other covariates indicated lower BMI in females but higher BMI in older adolescents. Interestingly, smoking habitually, sleeping time and having no family help with homework were negatively associated with adolescent BMI, but reading activity and watching TV presented positive associations. Finally, as expected, low maternal level of schooling correlated with higher levels of adolescent BMI. Hereafter, the peer group coefficients are the focus of the rest of the paper.

${ }^{23}$ As a supplemental test we used a Spatial Error Model procedure to test for the presence of unobservable effects regarding nominated friends' characteristics. LM statistics (LM-ERR and Robust LM-ERR) indicate that there is no need to include a structure of spatial dependence in the error term.
} 
variable of interest or the bi-directionality of the network effect. Whereas the first two columns account for the entire sample, the last two differentiate between male and female adolescents given that the amount of body fat changes with age and gender. However, as we have evidence of heteroskedasticity in the data [Pagan-Hall test $=101.53$, $\mathrm{p}$-value $=0.00$ ] we opted to re-run the equation (1) using the two-step General Method of Moments (GMM) estimator, which obtains a more efficient estimation than the IV estimator in the presence of heteroskedasticity of unknown form. In addition, we include the complete set of controls, assuming contextual effects and the two types of fixed effects. To ensure the strength of the instruments, a number of diagnoses were performed. ${ }^{24}$ The high values of the Kleibergen-Paap rk LM statistic ${ }^{25}$ of underidentification allow us to reject the null hypothesis that the equation is under-identified. Similarly, the low values of the Hansen's J statistics ( $p$-value $>0.05$ ) mean that we do not reject the null hypothesis and conclude that the instruments are orthogonal to the errors, thus suggesting that our instruments are reasonable. Compared to the critical values of Stock and Yogo (2005), the Wald F-statistics of weak identification show the bias of the GMM estimation to be less than 10\% (column 1), $15 \%$ (column 3) and 15\% (column 4) of the OLS bias. ${ }^{26}$

[Insert Table 4 about here]

The first column shows that the GMM estimate of the "nominated friends" peer effect is positive and, although weakly significant, indicates that when friends' mean BMI is one BMI unit higher then individual BMI is 0.37 units higher. Interestingly, this result is corroborated when the Limited Information Maximum Likelihood (LIML) estimator is used instead of the GMM estimator (column 2), giving rise to a statistically significant roughly similar coefficient (0.40). Note that the IV estimation notably increases the standard errors and hence reduces the statistical significance of the estimated parameters. As expected, the results in columns (3) and (4) confirm that while the GMM "nominated friends" peer effect for females is positive, again significant at 10\%, (0.43), for males this influence becomes insignificant. Overall, these findings suggest that neglecting the potential

\footnotetext{
${ }^{24}$ Regressions in Tables 4-5 use the instrument sets that maximize the Wald F-statistic of weak identification and minimize the Hansen statistic.

${ }^{25}$ When errors are heteroskedastic or serially correlated, the Anderson and Cragg-Donals statistics are not valid causing the null of underidentification to be rejected too often. The Kleibergen and Paap rk statistic was proposed to overcome this problem; it can be considered as a generalization of the Anderson canonical correlation rank statistic to the non-i.i.d. case. This test is automatically reported by Stata once we request any kind of robust covariance estimator.

${ }^{26}$ Note that these identification tests are necessary but not sufficient for valid IV's.
} 
endogeneity of peer group BMI may result in a downward bias in the estimated peer effects on adolescent weight. We can now conclude that the peer effect on adolescent weight found in our sample of Spanish students is notably stronger than the effects found by Renna et al. (2008) and Trogdon et al., (2008) using the US Add Health (In-Home sample) dataset.

\subsection{Social influences on different subgroups of students}

Fortunately, our dataset permits us to investigate the impact of peer contact on new and alternative subgroups of students. To our knowledge, this is the first study of this kind. Clearly, in order to provide information to help policy-makers combat the obesity epidemic among the young it is crucial to identify the groups of adolescents that are most vulnerable to external influences. Table 5 shows the results. Again, the same set of GMM estimations of equation (1) and identification strategy using the complete set of controls along with school- and neighbourhood-specific fixed effects are accounted for. As can be observed, overidentification and weak instrument tests suggest that our estimation results are reasonable. However, note that the number of observations has been reduced as a consequence of restricting the sample to the subjects who form the new groups of students.

In an effort to study vulnerability to social influences, in columns (1) and (2) our purpose is to focus on students who maintain the closest ties with each other. In column (1) we use the results of a yes/no survey question designed to ascertain whether the group of friends with which students maintain the most contacts is largely the same as in the previous academic year. Similarly, in column (2) we restrict the sample to those students who stated that they had been at the same school for the previous three years. With this information, we are able to exclude the students who do not have close friendships. Interestingly, as expected, the GMM results reveal a positive and larger impact of the "nominated friends" peer effect on adolescent BMI in the two samples (0.45 in column (1) and 0.53 in column (2)), reflecting that this group of students are more exposed to peer pressure from their friends.

[Insert Table 5 about here] 
The data also include a yes/no question in which students state whether they consider themselves as leaders in the classroom. This information helps to investigate how our peer pressure measure impact on a set of adolescents who do not have a leadership role. We assume that adolescents who consider themselves as leaders in their clique influence their friends more than their friends influence them. Hence, their exclusion from the sample should increase the peer pressure impact, since they are less likely to be influenced by peers. Although our findings in column (3) show a positive and significant GMM estimation of the BMI of "nominated friends" in this group of students $(0.34)$, the data do not show a much powerful impact than in the baseline case.

Finally, following Trogdon et al., (2008) in column (4) we examine the impact of peer contact defined at a broader level, namely assuming that all classmates constitute the reference group. ${ }^{27}$ These authors consider this peer measure (BMI of all classmates) to be more exogenous (given that the assignment to a certain class level depends on the year of birth) and estimate this effect by means of OLS methods. Although at the class level there are no selection problems, there is likely to be a reflection/simultaneity problem (i.e., the outcome of the individual may affect the outcome of the group). Thus we opted to estimate this peer influence by IV using as instruments average variables at the classroom level: mother's educational attainment, students' age and unhealthy behaviours (parental permission to go out, smoking cigarettes and pot and number of hours watching TV). Note that we use the class level-defined covariates that do not influence individual BMI, but do influence classmates' anthropometric measurement. Although not shown, there is enough variation in average BMI at the level of the entire classroom to sort out the differences between the peer effects and correlated effects.

The GMM estimation indicates a sizable, positive and statistically significant impact of the mean "all classmates" BMI on individual weight (0.63 vs. 0.37), being robust to the inclusion of school- and neighbourhood-specific fixed effects and a wide set of controls for other confounders. Note that here our identification strategy relies on having enough variations in peer group size (Lee, 2007). As observed by Eisenberg et al. (2005), this evidence is consistent with the fact that around twenty-five students share classrooms for almost thirty-five hours a week; therefore, it is highly likely that, although students share

\footnotetext{
${ }^{27}$ Of course, this kind of peer group is not expected to generate the same type of social influence as friendlevel peer pressure, which may operate through the imposition of a BMI standard or social norm (e.g., Burke and Heiland, 2007).
} 
their leisure time and study with a few specific students within their clique, they will also be influenced by the rest of their classmates. Similarly, students are unlikely to restrict themselves to their tightly-knit cliques and reject all other relationships at classroom level. Granovetter (2005) argues that smaller networks are connected to other networks by the strength of weak ties, and that this also occurs in classrooms. Therefore, information flows in a way that overlaps cliques. Again, note that the size of this peer effect derived from our sample of Spanish adolescents is larger than the coefficients reported by Trogdon et al., (2008) using the Add Health dataset.

\section{Concluding remarks}

This paper has extended the recent literature on peer effects and adolescent body weight on three new fronts. Firstly, our results support the hypothesis of a larger causal peer influence on adolescent BMI in a typical southern EU country (Spain) compared with the most analysed environment in the literature (the US), in accordance with the international evidence showing that peer group pressure on adolescent behaviour tends to vary greatly across countries. These findings are obtained from a single dataset on secondary school students in which peer influences are defined using classmate nominations and after accounting for a wide set of controls, fixed effects, the testing of correlated unobservables and the presence of contextual effects, and using IV estimation. Secondly, this study has applied the strategy described in Bramoullé et al. (2009) to identify social interactions based on the property of intransitivity in networks relationships. Thirdly, we investigate the impact of peer pressure on what is to our knowledge a newly defined subgroup of students in an attempt to assess which demographic groups are more vulnerable or influenceable to peer influence. The results show positive and significant alternative peer effects on adolescent BMI and broaden our understanding of the influence of friends on adolescent weight.

In all, the results reported in this study can help to explain the rapid increase in adolescent overweight in recent decades. The findings are consistent with the strand of the literature that supports the premise that overweight and obesity - like other health-related behaviours - are a social phenomenon. As such, weight-related behaviours of children and adolescents are affected not only by the family and the community, but also by peer contact which can shape self-perceived corporal image and ultimately affect adolescents' health 
status. The extent to which adolescents respond to social pressure may have important policy implications. The presence of social multiplier (spillover) effects acts to amplify the impacts of policy interventions aimed at reducing overweight/obesity levels among adolescents. Undoubtedly, public health interventions to curb the epidemic will require a co-ordinated effort between all the actors involved (e.g., health professionals and administrators, teachers, parents, food producers, retailers, caterers, advertisers, sport planners, urban architects, politicians, legislators, etc.). The issue is clearly a complex one.

Some caveats should be mentioned when interpreting the results. First, our analysis is based on a cross-section of schools, and the understanding of the dynamics of peer influence, which may change as adolescents age, needs to be investigated with the use of a panel dataset. Second, our measure of peer pressure is based on listed school friends, a definition that may ignore the role played by other influential friend or partner networks outside school. Third, the design of our dataset limits the use of other family background characteristics which might provide more relevant instruments. Finally, the paper does not analyze the mechanisms operating behind the influence of peers on adolescents' weight. 


\section{References}

Berndt, T. 1999. Friendship and friend's influence in adolescence, in: Muus R., Porton H. (eds.) Adolescent Behaviour and Society. MacGraw-Hill, Boston, 1999.

Bishop, J.H., Bishop, M., Bishop, M., Gelbwasser, L., Green, S., Peterson, E., Rubinsztaj, A. and Zuckerman, A. 2004. Why we harass nerds and freaks: a formal theory of student culture and norms. Journal of School Health 74(7): 235-251.

Bramoullé, Y., Djebbari, H. and Fortin, B. 2009. Identification of peer effects through social networks. Journal of Econometrics 150(1): 41-55.

Brunello, G. and D’Hombres, B. (2007) Does body weight affect wages? Evidence from Europe. Economics and Human Biology 5: 1-19.

Burke, M.A. and Heiland, F. (2007) Social dynamics of obesity. Economic Inquiry, 45(3), 571-591.

Calvó-Armengol, A., Patacchini, E. and Y. Zenou (2009) Peer effects and social networks in education. Review of Economic Studies, 76: 1239-1267.

Cawley, J. 2000. An instrumental variables approach to measuring the effect of body weight on employment disability. Health Services Research 35 (5, Part II): 1159-1179.

Cawley, J. and Burkhauser, R.V. 2008. Beyond the BMI: the value of more accurate measures of fatness and obesity in social science research. Journal of Health Economics 27: $519-529$.

Centers for Disease Control and Prevention CDC, National Center for Health Statistics, 2010. Health, United States, 2009: With Special Feature on Medical Technology. Hyattsville, MD. 2010.

Christakis, N.A. and Fowler, J.H. 2007. The spread of obesity in a large social network over 32 years. The New England Journal of Medicine, 357: 370-379.

Chou, S-Y., Grossman, M. and Saffer, H. 2004. An economic analysis of adult obesity: Results from the Behavioural Risk Surveillance System. Journal of Health Economics, 23: 565-587.

Clark, A.E. and Loheac, Y. 2007. It wasn't me, it was them! Social influence in risky behavior by adolescents. Journal of Health Economics 26, 763-784.

Cohen-Cole, E. and Fletcher, J.M. 2008. Is obesity contagious? Social networks vs. environmental factors in the obesity epidemic. Journal of Health Economics 27(5), 1382-1387. 
Cole, T. J., Bellizzi, M.C., Flegal, K.M. and Dietz, W.H. (2000) Establishing a standard definition for child overweight and obesity worldwide: international survey. British Medical Journal, 320: 1240-1243.

Cotterell, J. 2004. Social Networks and Social Influences in Adolescence. Routledge, NY.

Dietz, W.H. 1998. Health consequences of obesity in youth: childhood predictors of adult disease. Pediatrics 101: 518-525.

Eisenberg, M.E., Neumark-Sztainer, D., Story, M., Perry, Ch. 2005. The role of social norms and friends' influences on unhealthy weight-control behaviors among adolescent girls. Social Science and Medicine 60: 1165-1173.

Gaviria, A. and Raphael, S. 2001. School-based peer effects and juvenile behaviour. Review of Economics and Statistics 83(2): 257-268.

Granovetter, M. 2005. The impact of social structure on economic outcomes. Journal of Economic Perspectives 19(1): 33-50.

Halliday, T.J. and Kwak, S. 2009. Weight gain in adolescents and their peers. Economics and Human Biology 7(2): 181-190.

Halliday, T.J. and Kwak, S. 2012. What is a peer? The role of network definitions in estimation of endogenous peer effects. Applied Economics 44(3): 289-302.

Harris, J.E. and González, B. 2008. Asymmetric social interaction in economics: cigarette smoking among young people in the United States, 1992-1999. Journal of Health Economics, 27(2), 249-264.

Heckman, J.J., Stixrud, J. and Urzua, S. 2006. The effects of cognitive and noncognitive abilities on labor market outcomes and social behavior. Journal of Labor Economics 24(3): 411-482.

Irwing, C.E., Scott J.B. and Uhler Cart, C. 2002. America's adolescents: where have we been, where are we going? Journal of Adolescent Health 31(6): 91-121.

Kang, Ch. 2007. Classroom peer effects and academic achievement: quasirandomization evidence from South Korea. Journal of Urban Economics 61: 458-495.

Koplan, J.P., Liverman, C. T., Kraak, V.I. 2005. Preventing Childhood Obesity: Health in the Balance. Institute of Medicine of the National Academies. The National Academic Press, Washington, DC.

Lee, L.F. 2007. Identification and estimation of econometric models with group interactions, contextual factors and fixed effects. Journal of Econometrics 140(2): 333-374. 
Lundborg, P. 2006. Having the wrong friends? Peer effects in adolescent substance use. Journal of Health Economics 25: 214-233.

Manski, Ch. 1993. Identification of endogenous social effects: the reflection problem. Review of Economic Studies 60(3), 531-542.

Moffit, R. A. 2001. Policy interventions, low-level equilibria and social interactions. In S. N. Durlauf and H.P. Young (eds), Social Dynamics. Massachusetts: MIT Press, pp. 45-82.

Mora, T. 2010. BMI and Spanish labour status: evidence by gender from the city of Barcelona. The European Journal of Health Economics 11(3): 239-253

Norton, E.C., Lindrooth, R.C. and Ennett, S.T. 1998. Controlling for the endogeneity of peer substance use on adolescent alcohol and tobacco use. Health Economics 7(5): 439-453.

Reilly, J.J., Methven, E., McDowell, Z.C., Hacking, B., Alexander, D., Stewart, L. and Kelnar, C.J.H. 2003. Health consequences of obesity. Archives of Disease in Childhood 88: 748-752.

Renna, F., Grafova, I.B. and Thakur, N. 2008. The effect of friends on adolescent body weight. Economics and Human Biology 6: 377-387.

Soetevent, A.R. 2006. Empirics of the identification of social interactions; an evaluation of the approaches and their results. Journal of Economic Surveys 20(2): 193-228.

Trogdon, J.G., Nonnemaker, J. and Pais, J. 2008. Peer effects in adolescent overweight. Journal of Health Economics 27: 1388-1399.

WHO (2007) The Challenge of Obesity in the WHO European Region and the Strategies for Response. WHO Regional Office for Europe, Copenhagen, Denmark.

WHO (2008) Inequalities in Young People's Health. Health Behaviour in SchoolAged Children International Report from the 2005/2006 Survey. WHO Regional Office for Europe, Copenhagen, Denmark. 
Figure 1 Distribution of friends' nominations by BMI status

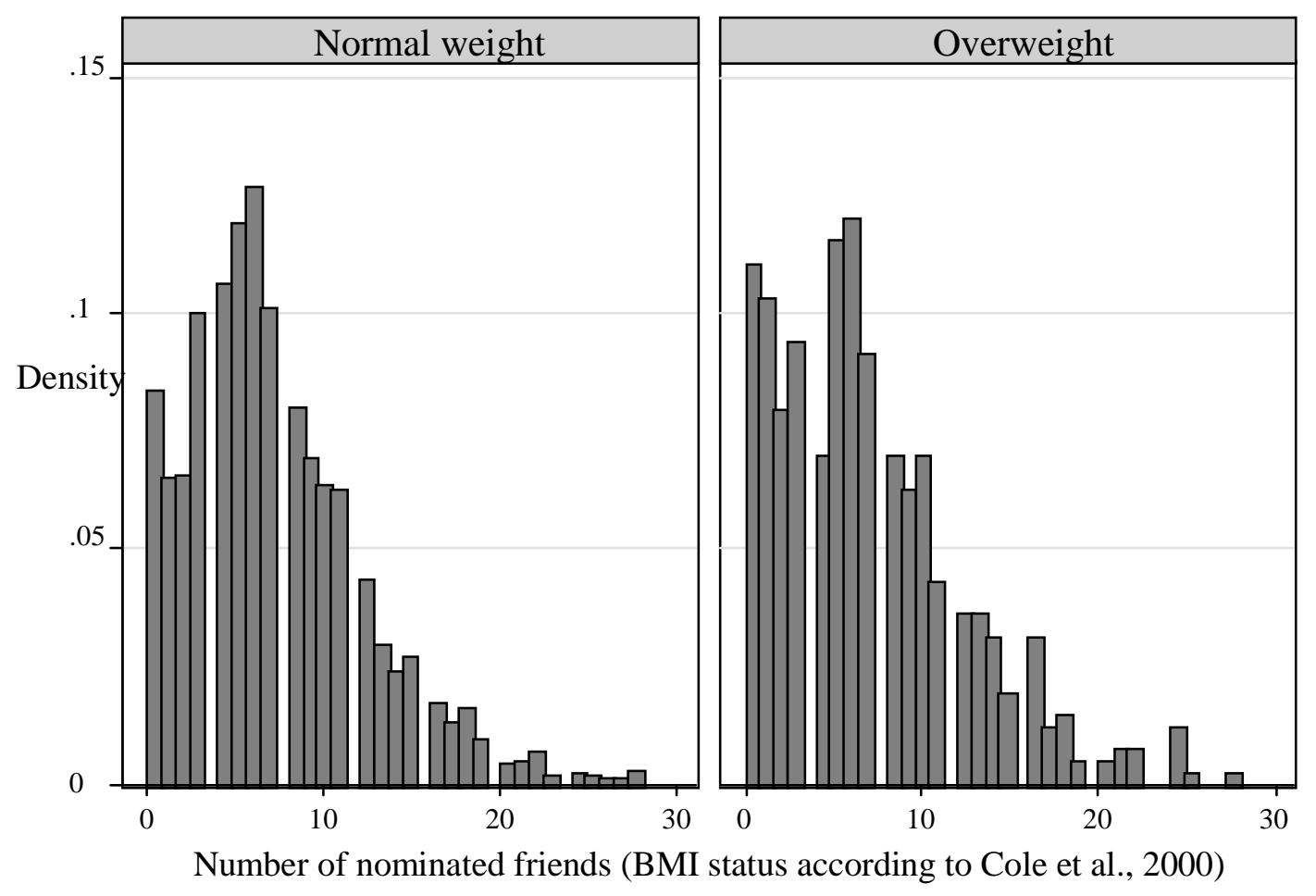


Figure 2 Enough variation in peers' BMI at school level

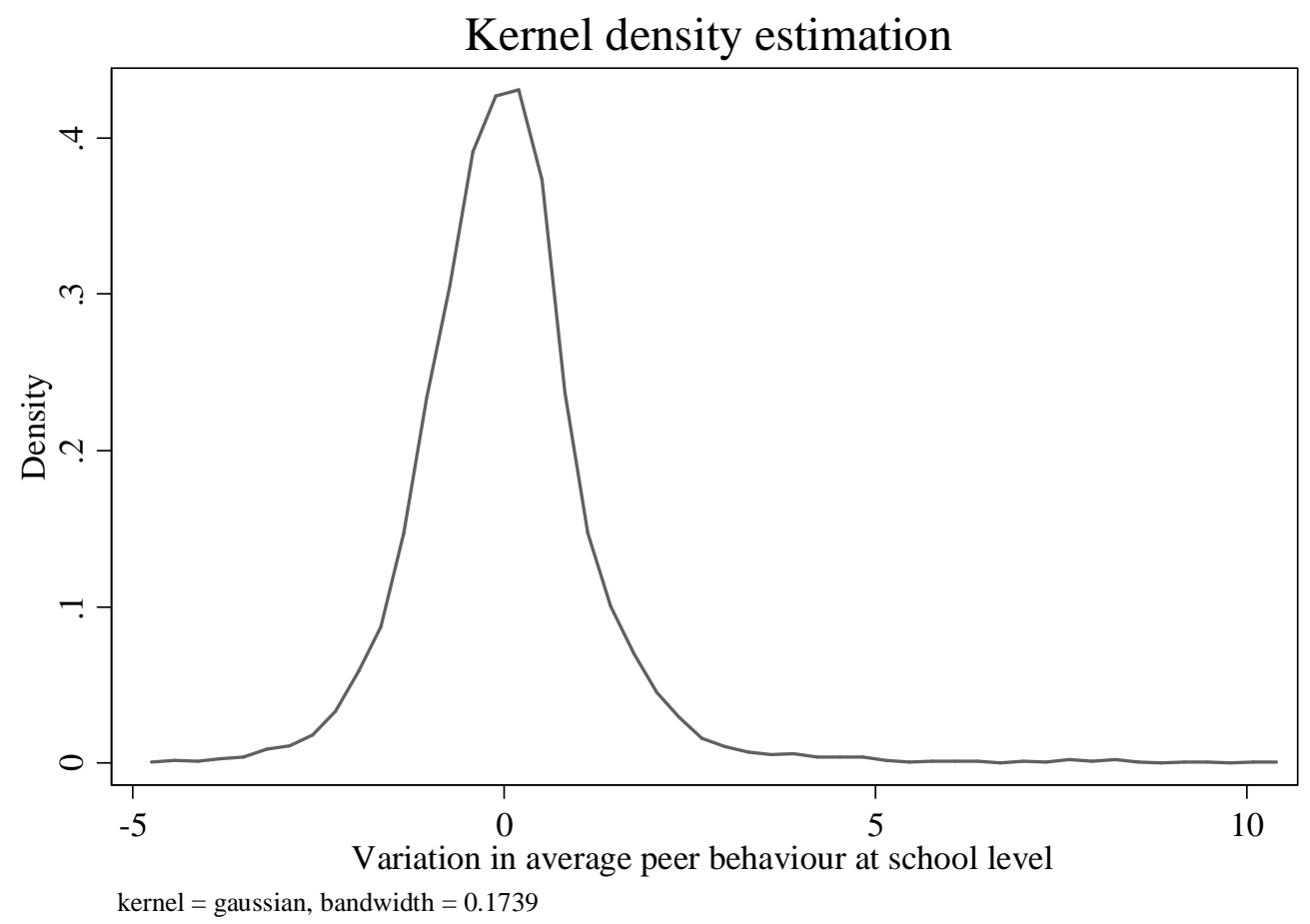


Age

Female

Immigrant status

Habitual smoker

Had drink over the last weekend

Sleeping time

Reading time

TV watching time

\section{Monoparental families}

Mother attains primary education

Mother attains higher education

Differential age student-mother

Mother's poor health status

No familiar involvement in homework

Share of mothers with higher education Share of female classmates
Age in years

Adolescent controls

$0-1$ dummy that equals 1 if female

$0-1$ dummy that equals 1 if immigrant

$0-1$ dummy that equals 1 if smokes daily

$0-1$ dummy that equals 1 if have drunk alcohol in the last weekend

Number of hours slept habitually per day

Number of weekly hours reading books, magazines, newspapers...

Number of daily hours watching TV

\section{Family controls}

0-1 dummy that equals 1 if parents are divorced, widowed or monoparental families

0 -1 dummy that equals 1 if adolescent's mother has primary education

0-1 dummy that equals 1 if adolescent's mother has university education

Difference in years between the mother and the adolescent

0-1 dummy that equals 1 if adolescent's mother has poor health

0-1 dummy that equals 1 if student does not receive any help from their parents

\section{Class-level controls}

Proportion of classroom mothers' attaining university education $\quad 0.30(0.18)$

$\begin{array}{ll}\text { Proportion of classroom mothers' attaining university education } & 0.30(0.18) \\ \text { Proportion of classroom female students } & 0.51(0.16)\end{array}$
$0.19(0.39)$

$0.13(0.34)$

$0.30(0.46)$

$28.71(4.60)$

$0.14(0.35)$

$0.47(0.50)$

Note: standard deviations are reported into brackets. 
Table 2 Friends' weight influence on adolescent BMI: OLS estimation

\begin{tabular}{|c|c|c|c|c|c|}
\hline & \multicolumn{5}{|c|}{ Adolescent BMI } \\
\hline & Column (1) & Column (2) & Column (3) & Column (4) & Column (5) \\
\hline Average BMI of "nominated friends" & $0.171(0.04)^{* * *}$ & $0.108(0.04)^{* *}$ & $0.091(0.04)^{* *}$ & $-0.017(0.05)$ & $-0.017(0.05)$ \\
\hline Conscientiousness factor & & $-0.814(0.41)^{* *}$ & $-0.850(0.41)^{* *}$ & $-0.942(0.42)^{* *}$ & $-0.915(0.50)^{*}$ \\
\hline Age & & $0.250(0.06)^{* * *}$ & $0.265(0.06)^{* * *}$ & $0.289(0.06)^{* * *}$ & $0.302(0.07)^{* * *}$ \\
\hline Female & & $-0.822(0.11)^{* * *}$ & $-0.815(0.12)^{* * *}$ & $-0.822(0.12)^{* * *}$ & $-0.870(0.14)^{* * *}$ \\
\hline Immigrant status & & $0.299(0.26)$ & $0.288(0.26)$ & $0.373(0.27)$ & $0.424(0.28)$ \\
\hline Habitual smoker & & $-0.372(0.15) * *$ & $-0.374(0.15)^{* *}$ & $-0.362(0.16) * *$ & $-0.340(0.17)^{*}$ \\
\hline Had drink over the last weekend & & $-0.112(0.12)$ & $-0.109(0.12)$ & $-0.129(0.12)$ & $-0.199(0.13)$ \\
\hline Sleeping time & & $-0.093(0.05)^{*}$ & $-0.094(0.05)^{*}$ & $-0.097(0.06)^{*}$ & $-0.101(0.06)^{*}$ \\
\hline Reading time & & $0.056(0.03)^{*}$ & $0.060(0.03)^{* *}$ & $0.063(0.03)^{* *}$ & $0.052(0.03)$ \\
\hline TV watching time & & $0.107(0.04)^{* * *}$ & $0.098(0.04)^{* *}$ & $0.084(0.04)^{* *}$ & $0.089(0.04)^{* *}$ \\
\hline Monoparental families & & $-0.003(0.14)$ & $0.007(0.14)$ & $0.013(0.14)$ & $-0.011(0.15)$ \\
\hline Mother attains primary education & & $0.571(0.15) * * *$ & $0.524(0.16)^{* * *}$ & $0.465(0.16)^{* * *}$ & $0.390(0.19)^{* *}$ \\
\hline Mother attains higher education & & $-0.244(0.12)^{*}$ & $-0.127(0.13)$ & $-0.138(0.14)$ & $-0.142(0.15)$ \\
\hline Differential age student-mother & & $-0.017(0.01)$ & $-0.014(0.01)$ & $-0.010(0.01)$ & $-0.007(0.01)$ \\
\hline Mother's poor health status & & $0.201(0.17)$ & $0.195(0.17)$ & $0.242(0.17)$ & $0.179(0.18)$ \\
\hline No familiar involvement in homework & & $-0.214(0.10) * *$ & $-0.223(0.10)^{* *}$ & $-0.254(0.11)^{* *}$ & $-0.279(0.12)^{* *}$ \\
\hline Share of mothers with higher education & & & $-0.903(0.32) * * *$ & $-0.432(0.59)$ & $-0.795(0.69)$ \\
\hline Share of female classmates & & & $-0.105(0.34)$ & $0.023(0.44)$ & $-0.188(0.48)$ \\
\hline School Fixed Effects & $\mathrm{NO}$ & $\mathrm{NO}$ & $\mathrm{NO}$ & YES & YES \\
\hline Neighbourhood Fixed Effects & $\mathrm{NO}$ & $\mathrm{NO}$ & $\mathrm{NO}$ & $\mathrm{NO}$ & YES \\
\hline $\mathrm{N}$ & 2,934 & 2,587 & 2,587 & 2,587 & 2,587 \\
\hline $\mathrm{R}^{2}$ & 0.1425 & 0.1993 & 0.2016 & 0.2264 & 0.3265 \\
\hline F-global & $269.44(0.00)$ & $40.57(0.00)$ & $37.63(0.00)$ & $19.92(0.00)$ & $58.78(0.00)$ \\
\hline
\end{tabular}


Table 3 Friends' weight influence on adolescent BMI: Extended OLS regressions

Adolescent BMI

\begin{tabular}{|c|c|c|}
\hline & Column (6) & Column (7) \\
\hline Average BMI of "nominated friends" & $-0.035(0.06)$ & $-0.028(0.05)$ \\
\hline Individual controls & YES & YES \\
\hline Family controls & YES & YES \\
\hline Class-level controls & YES & YES \\
\hline \multicolumn{3}{|l|}{ Peers' average characteristics } \\
\hline Conscientiousness factor & $0.294(1.28)$ & \\
\hline Age & $-0.051(0.05)$ & \\
\hline Female & $0.428(0.28)$ & \\
\hline Immigrant status & $0.654(0.55)$ & \\
\hline Habitual smoker & $-0.116(0.38)$ & \\
\hline Had drink over the last weekend & $-0.095(0.27)$ & \\
\hline Sleeping time & $0.101(0.07)$ & \\
\hline Reading time & $-0.008(0.06)$ & \\
\hline TV watching time & $0.032(0.08)$ & \\
\hline Monoparental families & $0.459(0.38)$ & \\
\hline Mother attains primary education & $0.287(0.42)$ & \\
\hline Mother attains higher education & $0.009(0.39)$ & \\
\hline Differential age student-mother & $-0.006(0.02)$ & \\
\hline Mother's poor health status & $0.715(0.43)^{*}$ & \\
\hline No familiar involvement in homework & $0.359(0.27)$ & \\
\hline Average pot consumption at classroom level & & $-0.399(0.63)$ \\
\hline Average drink consumption at classroom level & & $0.595(0.46)$ \\
\hline Average smoking consumption at classroom level & & $-0.673(0.67)$ \\
\hline Average binge behaviour at classroom level & & $0.049(0.49)$ \\
\hline Average physical activity at classroom level & & $-0.360(0.59)$ \\
\hline School \& Neighbourhood Fixed Effects & YES & YES \\
\hline $\mathrm{N}$ & 2,587 & 2,557 \\
\hline $\mathrm{R}^{2}$ & 0.3311 & 0.3283 \\
\hline F-global & $2.48(0.00)$ & $2.49(0.00)$ \\
\hline
\end{tabular}

Notes: Individual BMI was corrected due to self-reporting error. Adjusted robust standard errors for clustering at the classroom level were computed and reported in brackets. ${ }^{* *}$, ${ }^{* *}$ and $*$ denote statistical significance at 1,5 and $10 \%$ respectively. Regressions include a dummy variable for outliers and a constant term. 
Table 4 Friends' weight influence on adolescent BMI: GMM and LIML estimation

\begin{tabular}{|c|c|c|c|c|}
\hline & \multicolumn{4}{|c|}{ Adolescent BMI } \\
\hline & \multirow{2}{*}{$\begin{array}{c}\text { GMM } \\
\text { Whole sample } \\
\text { (1) }\end{array}$} & \multirow{2}{*}{$\begin{array}{c}\text { LIML } \\
\text { Whole sample } \\
\text { (2) }\end{array}$} & \multicolumn{2}{|c|}{ GMM } \\
\hline & & & $\begin{array}{c}\text { Male } \\
\text { (3) }\end{array}$ & $\begin{array}{c}\text { Female } \\
\text { (4) }\end{array}$ \\
\hline Average BMI of "nominated friends" & $0.371(0.21)^{*}$ & $0.398(0.19)^{* *}$ & $0.338(0.30)$ & $0.431(0.25)^{*}$ \\
\hline Individual controls & YES & YES & YES & YES \\
\hline Family controls & YES & YES & YES & YES \\
\hline Class-level controls & YES & YES & YES & YES \\
\hline Peers' average characteristics & YES & YES & YES & YES \\
\hline School \& Neighbourhood Fixed Effects & YES & YES & YES & YES \\
\hline $\mathrm{N}$ & 1,916 & 1,916 & 1,001 & 915 \\
\hline $\mathrm{R}^{2}$ & 0.1160 & 0.1476 & 0.0876 & 0.1348 \\
\hline F-statistic (global) & $9.75(0.00)$ & $375.85(0.00)$ & $5.81(0.00)$ & $6.39(0.00)$ \\
\hline Wald F-statistic-weak identification test & $>10 \%(26.18)$ & & $>15 \%(18.04)$ & $>15 \%(16.34)$ \\
\hline Under identification (Kleibergen-Paap rk LM stat.) & $118.78(0.00)$ & & $73.61(0.00)$ & $82.07(0.00)$ \\
\hline Hansen's J statistic ( $\mathrm{p}$-value) & $4.89(0.18)$ & & $5.42(0.14)$ & $1.40(0.71)$ \\
\hline
\end{tabular}

Notes: Individual BMI was corrected due to self-reporting error. As instruments we used mean attributes (mothers' years of education, average age and the share of single/divorced parents) of the respondents' friends-of-friends who are not friends with the respondent (Bramoullé et al. 2009). Adjusted robust standard errors for clustering at the classroom level were computed and reported in brackets. Then, ${ }^{* *},{ }^{* *}$ and $*$ denote statistical significance at 1,5 and $10 \%$ respectively. Regressions include a dummy variable for outliers and a constant term. 
Table 5 Friends' weight influence on adolescent BMI in different subsamples: GMM estimation

\begin{tabular}{|c|c|c|c|c|}
\hline & \multicolumn{3}{|c|}{ Adolescent BMI } & \multirow[b]{3}{*}{$\begin{array}{c}\text { Whole sample } \\
\text { (4) }\end{array}$} \\
\hline & \multicolumn{3}{|c|}{ GMM Estimation } & \\
\hline & $\begin{array}{l}\text { Last year } \\
\text { friends } \\
\text { (1) }\end{array}$ & $\begin{array}{l}\text { No changed } \\
\text { school last } \\
\text { three years } \\
\text { (2) }\end{array}$ & $\begin{array}{c}\text { No leadership } \\
\text { (3) }\end{array}$ & \\
\hline Average BMI of "nominated friends" & $0.453(0.21)^{* *}$ & - & - & - \\
\hline Average BMI of "nominated friends" & - & $0.534(0.24)^{* *}$ & - & - \\
\hline Average BMI of "nominated friends" & - & - & $0.339(0.21)^{*}$ & - \\
\hline Average BMI of all classmates & - & - & - & $0.633(0.09)^{* * *}$ \\
\hline Individual controls & YES & YES & YES & YES \\
\hline Family controls & YES & YES & YES & YES \\
\hline Class-level controls & YES & YES & YES & YES \\
\hline Peers' average characteristics & YES & YES & YES & - \\
\hline School \& Neighbourhood Fixed Effects & YES & YES & YES & YES \\
\hline $\mathrm{N}$ & 1,505 & 1,601 & 1,751 & 2,754 \\
\hline $\mathrm{R}^{2}$ & 0.0815 & 0.0332 & 0.1117 & 0.2825 \\
\hline F-global & $7.50(0.00)$ & $6.02(0.00)$ & $10.40(0.00)$ & $85.18(0.00)$ \\
\hline Wald F-statistic-weak identification test & $>10 \%(29.61)$ & $>15 \%(23.44)$ & $>10 \%(25.22)$ & $>10 \%(14.25)$ \\
\hline Under identification (Kleibergen-Paap rk LM stat.) & $136.32(0.00)$ & $108.24(0.00)$ & $116.13(0.00)$ & $50.76(0.00)$ \\
\hline Hansen's J statistic (p-value) & $5.80(0.12)$ & $3.42(0.33)$ & $5.65(0.13)$ & $5.40(0.61)$ \\
\hline
\end{tabular}

Notes: Individual BMI was corrected due to self-reporting error. In Columns (1) to (3) we used as instruments mean attributes (mothers' years of education, average age and the share of single/divorced parents) of the respondents' friends-of-friends who are not friends with the respondent (Bramoullé et al. 2009). In column (4) instruments were average mother's educational attainment, students' age and unhealthy behaviours defined at the classroom level. Adjusted robust standard errors for clustering at the classroom level were computed and reported in brackets. Then, $* * *, * *$ and $*$ denote statistical significance at 1,5 and $10 \%$ respectively. Regressions include a dummy variable for outliers and a constant term. 